\title{
Investigation of bioactivities of endophytes of Ficus carica L. Fam Moraceae
}

\author{
Randa Abdou ${ }^{1 *}$, Mariam Mojally ${ }^{2}$ and Gouda H. Attia ${ }^{3}$
}

\begin{abstract}
Background: The medicinal plant Ficus carica L., inhabiting southwest regions of Asia, is known for its wide ethnopharmacological applications. In traditional medicine, it has been applied as a treatment of respiratory, gastrointestinal and cardiovascular disorders, among others. Recent studies confirmed antimicrobial and anticancer activities for the plant extract. To find out whether endophytes of F. carica contribute to its biological activities, endophytes of the aerial parts of the plant were isolated and examined for anticancer and antimicrobial effects.

Results: The isolated species were identified as Chaetomium globosum, Penicillium oxalicum, Alternaria alternata, Fusarium proliferatum and Aspergillus neoniger. An anticancer assay was carried out on the extracts of fungal strains against human umbilical vein endothelial cells (HUVEC), human immortalized myelogenous leukemia cell line (K-562) and human immortal cervical cancer cell line (HeLa). Results revealed antiproliferative effects for all endophytic strains against HUVEC and $\mathrm{K}-562$ with $\mathrm{Gl}_{50}$ values ranging from 4.75 to $13.75 \mu \mathrm{g} \mathrm{mL} \mathrm{L}^{-1}$ as well as cytotoxicity against HeLa with $\mathrm{CC}_{50}$ ranging from 8.25 to $18.75 \mathrm{\mu g} \mathrm{mL}^{-1}$. The antimicrobial activity of the extracts was tested against several test strains in agar diffusion assay, and MIC values were determined by the broth microdilution method. All strain extracts exerted antibacterial and antifungal activities with highest antifungal effect observed for $A$. neoniger extract $\left(\mathrm{MIC}=3.75 \mu \mathrm{g} \mathrm{mL}^{-1}\right)$.

Conclusions: These results support the assumption that endophytes of F. carica contribute to the plant's reported antimicrobial and anticancer activities and its corresponding applications in traditional medicine.
\end{abstract}

Keywords: Endophytes, Ficus carica, Symbiosis, Anticancer, Antimicrobial

\section{Background}

In all ecological systems, fungi are found to play important roles. Parasitic and pathogenic fungal species often attack many types of organisms including plants, humans, animals and other fungi. Saprotrophic fungal species were reported to be important for nutrients cycling. Additionally, fungi may form mutualistic relationships with other organisms such as those of endophytes or lichens (Verma et al. 2009). Endophytes are microorganisms living symbiotically within plant tissues without diseasing them and are found in most plant

\footnotetext{
*Correspondence: rfabdou@uqu.edu.sa

1 Pharmacognosy Department, Faculty of Pharmacy, Umm Al-Qura University, Makkah, Kingdom of Saudi Arabia

Full list of author information is available at the end of the article
}

species studied so far (Saikkonen 2004). Since endophytes are considered as promising sources of bioactive natural products, it is important to select a suitable host plant with promising bioactive endophytes. Plants growing in special environmental conditions are resistant to stress and are recommended for the study of their endophytes. Plants employed in traditional herbal medicine are also a promising source of bioactive endophytes (Strobel 2006). Ficus carica, commonly known as fig, belongs to the first plants cultivated by humans and inhabits southwest regions of Asia and the eastern Mediterranean areas (Mawa et al. 2013). In traditional medicine, it has found wide applications for the treatment of various conditions including respiratory, gastrointestinal and cardiovascular disorders and the paste of the fruit was used to exert anti-inflammatory, analgesic and antispasmodic 
effects (Mawa et al. 2013; Barolo et al. 2014). Although $F$. carica growing in the tropical environment of southwest the Kingdom of Saudi Arabia (KSA) is known for its nutritional value and ethnopharmacological applications, nothing is known about its endophytes. A recent study reported the frequency of endophyte colonization in the different plant parts of $F$. benghalensis growing in India and stated that the growth environment and tissue type of the host plant determine endophyte composition in that host (Suryanarayanan and Vijaykrishna 2001). More recently, F. carica growing in India was studied for the potential use of its endophytes as biocontrol agents and their activity against phytopathogens was examined (Rosli et al. 2020). Now the question arises about the role of endophytes of $F$. carica in its biological actions. Previous studies suggested that endophytes might contribute to the biological effects observed for host plants (Kour, et al. 2020). The antimicrobial activity of Ficus carica was confirmed by a study testing the effect of the plant extract on several bacterial strains (E. coli, S. aureus, $S$. sanguinis, S. criceti, S. gordonii and S. anginosus). Results revealed potent antimicrobial activity for the methanolic plant extract with MIC values ranging from 0.313 to $5 \mathrm{mg} / \mathrm{mL}$ against the different strains (Joeng et al. 2009). Another study investigated the antifungal effects of $F$. carica extracts and revealed growth inhibition of C. albicans and Microsporum canis by the plant extract with MIC of $500 \mu \mathrm{g} / \mathrm{mL}$ and $75 \mu \mathrm{g} / \mathrm{mL}$, respectively (Aref 2010). Furthermore, the anticancer activity of the plant was recently studied on Huh7it liver cancer cells and the results revealed an $\mathrm{IC}_{50}$ value of $>653 \mu \mathrm{g} / \mathrm{mL}$ for the extract of the plant's leaves (Purnamasari 2019).

This study presents the investigation of the endophytes of the medicinal plant Ficus carica fam. Moraceae growing in the tropical region of Makkah, KSA, and their antimicrobial and anticancer activities to find out whether they contribute to the reported antimicrobial and anticancer activities of the plant. This investigation represents the first step in the search for new anticancer agents required to meet community needs. Many biological activities were previously reported for the genus Ficus such as antioxidant, anti-inflammatory, laxative and hypotensive effects (Vieira and Kijjoa 2005). In traditional medicine, it was used for the treatment of cough, urinary tract infections, fever and tuberculosis. A study conducted on the Cameroonian medicinal plant Ficus asperifolia revealed anticancer activity of its extract against ovarian cells resistant to the standard anticancer drug cisplatin. Another study reported the fruit extract of $F$. benghalensis to exhibit antitumor activity (Abd El Raheim et al. 2013).

So far, investigation of Ficus species focused mainly on the plant itself, but the bioactivity of its endophytes was rarely studied. In an attempt of discovering whether endophytes of $F$. carica contribute to the known activities of the plant, the isolation of endophytes and investigation of their biological activities are presented in this study.

\section{Methods}

\section{Plant collection and isolation of endophytes}

The plant was collected from Wadi Fatima, Makkah, Saudi Arabia, and identified by Dr. Hany Gouda, Department of Pharmacognosy, College of Pharmacy, Najran University, Saudi Arabia. A voucher specimen (UQU2019-1) of the plant was kept at the herbarium of the Pharmacognosy Department, Faculty of Pharmacy, Umm Al-Qura University. Handling of the plant material was started by cutting it into small pieces, washing with demineralized, sterilized water and afterward treating its surface with $70 \%$ ethanol for 1-2 min followed by air-drying under a laminar flow hood. This aimed to eliminate contaminating microbes on the surface of the plant material. To confirm effective sterilization, $1 \mathrm{ml}$ of the final rinse was placed onto nutrient agar media and incubated at $37^{\circ} \mathrm{C}$ for $24 \mathrm{~h}$. The outer tissues of the sterilized plant samples were removed with a sterile scalpel, and inner tissues were dissected under sterile conditions and planted onto malt agar (MA) plates containing $0.1 \mathrm{~g}$ streptomycin as an antibiotic. After an incubation time of about 3-4 weeks at room temperature, hyphal tips of the fungi were transferred to fresh malt agar medium. To eliminate the possibility of contamination, duplicate plates were prepared, and pure strains were isolated by repetition of inoculation. MA medium consisting of agar-agar (15.0 g), malt extract (15.0 g), distilled water (to $1000 \mathrm{~mL}$ ), pH (7.4-7.8 adjusted with $\mathrm{NaOH} / \mathrm{HCl}$ ), was used for the storage of fungal cultures for a short term. Chloramphenicol or streptomycin $(0.2$ or $0.1 \mathrm{~g}$, respectively) was added to the medium to inhibit bacterial growth during the isolation of endophytic fungi from plant tissues (Zhang et al. 2006).

\section{Cultivation of endophytic strains}

Each endophytic fungus was cultivated for 14 days on potato dextrose agar (PDA) at $23{ }^{\circ} \mathrm{C}$. The mycelium was divided into 12 pieces, and each one was used to inoculate a 1-L Erlenmeyer flask that contained $250 \mathrm{~mL}$ of a culture medium composed of glucose $10 \mathrm{~g} / \mathrm{L}$, malt extract $20 \mathrm{~g} / \mathrm{L}$, Soybean flour $2 \mathrm{~g} / \mathrm{L}$, yeast extract $1 \mathrm{~g} / \mathrm{L}, \mathrm{KH}_{2} \mathrm{PO}_{4}$ $1 \mathrm{~g} / \mathrm{L}$ and $\mathrm{MgSO}_{4} .7 \mathrm{H} 2 \mathrm{O} 0.5 \mathrm{~g} / \mathrm{L}$. Incubation was carried out for 21 days $\left(23{ }^{\circ} \mathrm{C}\right)$ under static conditions (Stevens 1981). For extraction, culture filtrate and mycelium were homogenized in each Erlenmeyer flask and the homogenized mixture was macerated in $200 \mathrm{~mL}$ EtOAc for $24 \mathrm{~h}$, which was then collected by decantation. The obtained 
ethyl acetate extract was then evaporated to dryness and defatted with $\mathrm{n}$-hexane to get the crude extract.

\section{Identification of fungal strains}

Identification of the fungal strains was carried out using the standard protocol based on their cultural and microscopic properties (Barnett and BB 1998) and was confirmed using molecular biological techniques through DNA extraction. Then, amplification was carried out by polymerase chain reaction (PCR), and finally, sequencing was performed using ITS1 (5'-TCCGTAGGTGAA CCTGCGG-3') and ITS4 (5'-TCCTCCGCTTATTGA TATGC-3') primers. For DNA extraction from the fungal culture, a piece of $0.5 \mathrm{~cm}^{2}$ was cut in the MA plate and was freeze-dried in a 2-ml tube. One hundred microliters of rapid lysis solution from Sigma REDExtract-N-Amp ${ }^{\text {TM }}$ Plant PCR Kit was added to it followed by $10-\mathrm{min}$ incubation at $95{ }^{\circ} \mathrm{C}$ and vortex with glass beads was sometimes required. For neutralization after heating, $100 \mu \mathrm{L}$ of dilution solution was added. DNA amplification was carried out by performing a polymerase chain reaction (PCR) in which Sigma REDExtract-N-Amp ${ }^{\mathrm{TM}}$ Plant PCR Kit's polymerase and different primers were employed. To $46 \mu \mathrm{L}$ of the polymerase master mixture, $4 \mu \mathrm{L}$ of DNA template was added which consisted of $18 \mu \mathrm{L}$ RNA (ribonucleic acid)-free water, $25 \mu \mathrm{L}$ REDExtract-N-Amp ${ }^{\text {TM }}$ Plant PCR solution and $3 \mu \mathrm{L}$ of each primer $(10 \mathrm{pmol} / \mu \mathrm{L}$ each). The $50 \mu \mathrm{L}$ solution sample was then subjected to the PCR (Michaelsen 2006; Raja 2017).

\section{PCR protocol, DNA extraction, amplification and sequencing}

Denaturation was performed at $95^{\circ} \mathrm{C}$ for 15 min followed by denaturation at $95^{\circ} \mathrm{C}$ for $1 \mathrm{~min}$, and finally, annealing was carried out at $56{ }^{\circ} \mathrm{C}$ for $0.5 \mathrm{~min}$. The extension process was performed at $72{ }^{\circ} \mathrm{C}$ for $1 \mathrm{~min}$ followed by final extension at $72{ }^{\circ} \mathrm{C}$ for $10 \mathrm{~min}$. All steps were carried out 35 times except initial denaturation and final extension. To confirm that PCR has been successfully carried out, the gel was transferred into the ultraviolet transilluminator after electrophoresis. By comparison with DNA ladder, PCR products were found to possess the right size of about $550 \mathrm{bp}$. The band was accurately excised from the gel and inserted into an Eppendorf tube. As indicated by the protocol of the manufacturer, the PCR product was isolated from the gel slice by the aid of Sigma GenElute $^{\mathrm{TM}}$ Gel Extraction Kit. Three-gel volume of the solubilization solution was added to the gel and heated at $50-60{ }^{\circ} \mathrm{C}$ for $15 \mathrm{~min}$. For precipitation of the DNA, one gel volume of isopropanol was added. Afterward, the solution was applied to the binding column followed by spinning at 13,000 rpm for $1 \mathrm{~min}$. Then, the washing solution was added to remove any impurities which was followed by spinning at 13,000 rpm. The collection tube was finally changed, and the elution solution was added, followed by spinning for elution of DNA from the column. The concentration of DNA was determined using Nano drop 2000, and the PCR product was stored at $-20{ }^{\circ} \mathrm{C}$ until sequencing. DNA sequencing was carried out by the addition of $30 \mathrm{ng}$ of PCR product to $3.2 \mathrm{pmol}$ primer, $8 \mu \mathrm{L}$ big dye and $20 \mu \mathrm{L}$ RNA-free water. Afterward, this mixture was subjected to PCR (Bio-Rad, USA) starting with initial denaturation at $96{ }^{\circ} \mathrm{C}$ for $1 \mathrm{~min}$ followed by 35 cycles of denaturation at the same temperature for $10 \mathrm{~s}$ and annealing at $50{ }^{\circ} \mathrm{C}$ for $5 \mathrm{~s}$ followed by extension at $60^{\circ} \mathrm{C}$ for $4 \mathrm{~min}$. The obtained products were stored at $8{ }^{\circ} \mathrm{C}$ and then subjected to direct sequencing, and the sequences were aligned through Clustalw ${ }^{\circledR}$ and Boxshade $^{\circledR}$ Web sites. Basic local alignment search tool (BLAST) search of the FASTA sequence was performed with the option "nr" on the BLAST homepage, National Center for Biotechnology Information (NCBI), Bethesda, USA (Elix et al. 1982; Fernandez 1998).

\section{Biological screening methods Antimicrobial screening}

Antimicrobial activities were studied by agar diffusion tests qualitatively according to the National Committee for Clinical Laboratory Standards (NCCLS) guidelines (Wayne 2002; Afonin 2003) and by using the broth microdilution method to determine the minimal inhibitory concentration (MIC) quantitatively according to the NCCLS guidelines (Wayne 2002; Wayne 2000). Of each investigated methanolic extract, $50 \mu \mathrm{L}$ was serially diluted by factor two with the Roswell Park Memorial Institute medium (LONZA Verviers SPRL, Belgium). Then, the wells were inoculated with $50 \mu \mathrm{L}$ of the tested microorganism, Aspergillus terreus, to get a concentration of $6 \times 10^{3} \mathrm{CFU} \mathrm{mL} \mathrm{mL}^{-1}$. After incubation of microtiter plates at $37^{\circ} \mathrm{C}$ for $24 \mathrm{~h}$, the MIC values were read as the lowest dilution of compound allowing no visible growth by the aid of a Nepheloscan Ascent 1.4 automatic plate reader (Lab Systems, Vantaa, Finland). To perform the agar diffusion assay, all tested microorganisms were suspended in melted agar medium and then poured into Petri dishes in which holes of $9 \mathrm{~mm}$ diameter were cut followed by filling $50 \mu \mathrm{L}$ of a $100 \mathrm{mg} / \mathrm{L}$ solution of endophytic extract. The obtained zones of inhibition were measured with a ruler after incubation overnight.

\section{Anticancer assay}

Human umbilical vein endothelial cells (HUVEC), K-562 and HeLa cell line were cultured in Dulbecco's modified Eagle's medium (DMEM), Roswell Park Memorial Institute medium (RPMI 1640) and RPMI 1640 medium, respectively. The cell culture medium was supplemented 
with $10 \mathrm{~mL} \mathrm{~L}^{-1}$ ultraglutamine $1,500 \mu \mathrm{L} \mathrm{L}^{-1}$ gentamicin sulfate and $10 \%$ heat-inactivated fetal bovine serum at $37{ }^{\circ} \mathrm{C}$ in high-density polyethylene flasks, and the anticancer assay was performed as previously reported (Abdou 2010; Macabeo 2013). Before being diluted with DMEM, each of the tested extracts was dissolved in DMSO for the antiproliferative assay. At the logarithmic growth phase, adherent cells were harvested after soft trypsinization with $0.25 \%$ trypsin in PBS including $0.02 \%$ EDTA (Biochrom KG L 2163). Approximately 10.000 cells were seeded for each experiment with $0.1 \mathrm{~mL}$ culture medium per well of the 96-well microplates (NUNC 167008).

The cytotoxic assay was carried out on HeLa cells which were pre-incubated for $48 \mathrm{~h}$ without the test substances. Dilutions of the tested samples were carefully carried out on the sub-confluent monolayers of HeLa cells after preincubation. HeLa cells were incubated for $72 \mathrm{~h}$ at $37^{\circ} \mathrm{C}$ in a humidified atmosphere and $5 \% \mathrm{CO}_{2}$ with dilutions of the tested samples. In order to evaluate the influence of the tested sample on proliferation of K-562 cells, viable cell numbers in multiwell plates were measured by the aid of the CellTiter-Blue ${ }^{\circledR}$ assay. Resazurin was used as an indicator dye to determine the cells' metabolic capacity which was considered as an indicator of cell viability. Resazurin was reduced into the highly fluorescent resorufin by viable cells of the untreated control. Nonviable cells on the contrary lacked the ability of resazurin reduction and consequently did not produce fluorescence. Accordingly, there is a proportional relationship between the number of viable cells and the fluorescence produced. Glutaraldehyde was used to fix the adherent HUVEC and HeLa cells which were stained using 0.05\% methylene blue for $15 \mathrm{~min}$. The stain was washed gently and eluted with $0.33 \mathrm{~N} \mathrm{HCl}(0.2 \mathrm{~mL})$ in the wells. In SUNRISE microplate reader (TECAN), at $660 \mathrm{~nm}$ optical densities were measured. The concentration for $50 \%$ of maximal inhibition of cell proliferation $\left(\mathrm{GI}_{50}\right)$ and the $50 \%$ cytotoxic concentration $\left(\mathrm{CC}_{50}\right)$ of the tested samples were determined by measuring the intersection of the dose response curve with the $50 \%$ line, compared to untreated control. Magellan software (TECAN) was used for comparison of the obtained values.

\section{Results}

Five endophytic fungi (Chaetomium globosum, Penicillium oxalicum, Alternaria alternata, Fusarium proliferatum and Aspergillus neoniger) were isolated from the medicinal plant Ficus carica growing in Makkah region, KSA. Identification of these fungal strains was carried out using the standard protocol based on their cultural and microscopic properties (Barnett and BB H, 1998) and was re-confirmed by using molecular biology procedures by comparison of the isolated DNA sequence with those found in the gene bank. All of them showed 96-100\% similarity, using a PCR program previously described by Rychlik and co-workers (Rychlik et al. 1990).

To investigate the biological activities of the isolated endophytes, their methanolic extracts were subjected to antimicrobial screening in agar diffusion assay. The extracts were tested against several microbial species (Table 1). Results revealed the presence of antimicrobial activity against most test strains for all endophytic extracts. The highest activities were observed for Chaetomium globosum, Penicillium oxalicum and A. neoniger especially against Aspergillus terreus, Bacillus subtilis, Escherichia coli and Staphylococcus aureus (Table 1). Potent antifungal activity was exerted by the extract of Chaetomium globosum against all tested fungal strains. The MIC of each strain was determined against $A$. terreus, the most sensitive test strain to almost all extracts, using methanol as a negative and ampho-

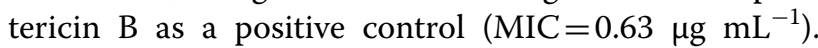
Results revealed MIC values of 5.67, 7.82, 4.26, 8.15 and $3.75 \mu \mathrm{g} \mathrm{mL}^{-1}$ for the extracts of strains Chaetomium globosum, Penicillium oxalicum, Alternaria alternata, Fusarium proliferatum and Aspergillus neoniger, respectively. Accordingly, A. neoniger exhibited highest antifungal activity against $A$. terreus. Relatively potent antifungal effects were also observed for A. alternata and C. globosum against $A$. terreus (MIC of 4.26 and $5.67 \mu \mathrm{g} \mathrm{mL}{ }^{-1}$, respectively).

Table 1 Antifungal activity of the extracts of isolated endophytes

\begin{tabular}{|c|c|c|c|c|c|c|}
\hline Microorganism & A. alternata & F. proliferatum & C. globosum & P. oxalicum & A. neoniger & $\begin{array}{l}\text { Amphotericin } \\
B\end{array}$ \\
\hline Saccharomyces cerevisae & 15 & 16 & 22 & 16 & 22 & 28 \\
\hline Candida albicans & 16 & 13 & 24 & 17 & 25 & 29 \\
\hline Penicillium notatum & 19 & 15 & 35 & 22 & 25 & 30 \\
\hline Penicillium avellaneum & 20 & 15 & 37 & 22 & 27 & 32 \\
\hline Aspergillus terreus & 25 & 18 & 32 & 30 & 34 & 35 \\
\hline
\end{tabular}

Antifungal activity is measured in terms of the diameter of the inhibition zone in millimeters 
Additionally, extracts of these endophytes were subjected to an anticancer and cytotoxic assay against the cell lines HUVEC, K-562 and HeLa. Results revealed antiproliferative effects for all endophytic strains against HUVEC and K-562 with $\mathrm{GI}_{50}$ values ranging from 4.75 to $13.75 \mu \mathrm{g} \mathrm{mL} \mathrm{m}^{-1}$ as well as cytotoxicity against HeLa with $\mathrm{CC}_{50}$ ranging from 8.25 to $18.75 \mu \mathrm{g} \mathrm{mL}{ }^{-1}$ (Fig. 1, $2,3)$. As for the examined cytotoxicity on HeLa cell line (Fig. 3), all tested endophytic extracts showed significant cytotoxic activity with C. globosum and A. neoniger exerting the strongest cytotoxic effects with $\mathrm{CC}_{50}$ values of $8.25 \mu \mathrm{g} \mathrm{mL} L^{-1}$ and $9.21 \mu \mathrm{g} \mathrm{mL}^{-1}$, respectively. Weakest cytotoxicity was observed for the extract of $P$. oxalicum $\left(\mathrm{CC}_{50}=18.75 \mu \mathrm{g} \mathrm{mL} \mathrm{m}^{-1}\right)$ and moderate effect for $F$. proliferatum $\left(\mathrm{CC}_{50}=15.25 \mu \mathrm{g} \mathrm{mL} \mathrm{m}^{-1}\right)$. The antiproliferative assay revealed $A$. neoniger of being of highest cytostatic activity against both HUVEC (Fig. 1) and $\mathrm{K}-562$ cell lines (Fig. 2) with $\mathrm{GI}_{50}$ values of $7.75 \mu \mathrm{g} \mathrm{mL}^{-1}$ and $4.75 \mu \mathrm{g} \mathrm{mL} \mathrm{m}^{-1}$, respectively. All remaining extracts exerted rather moderate antiproliferative effects against HUVEC and K-562 with lowest cytostatic activity against HUVEC exerted by $A$. alternata $\left(\mathrm{GI}_{50}=13.52 \mu \mathrm{g} \mathrm{mL}^{-1}\right)$ and against $\mathrm{K}-562$ by C. globosum $\left(\mathrm{GI}_{50}=13.75 \mu \mathrm{g} \mathrm{mL}^{-1}\right)$. The extract of $P$. oxalicum showed almost identical antiproliferative effects against HUVEC and K-562 with $\mathrm{GI}_{50}$ values of $11.54 \mu \mathrm{g} \mathrm{mL} L^{-1}$ and $11.95 \mu \mathrm{g} \mathrm{mL}^{-1}$,

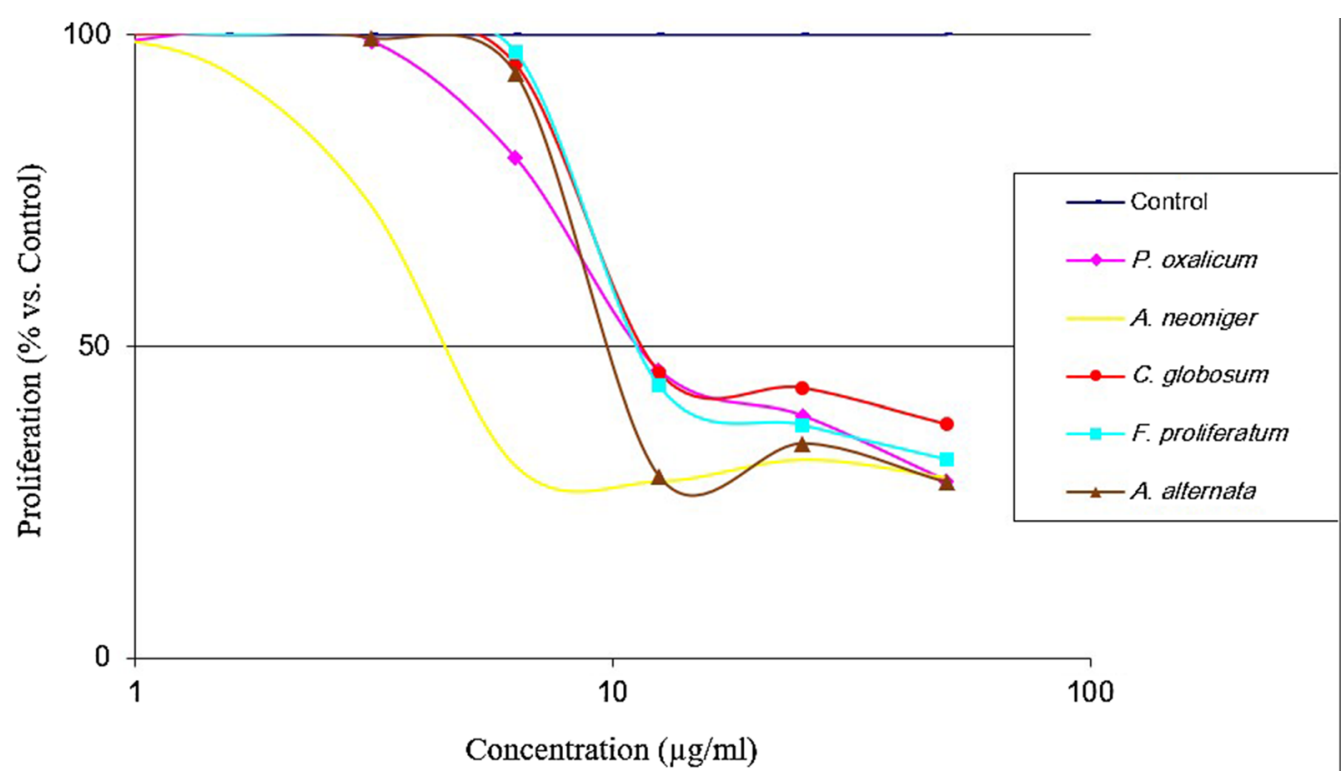

Fig. 1 Antiproliferative effect on K-562

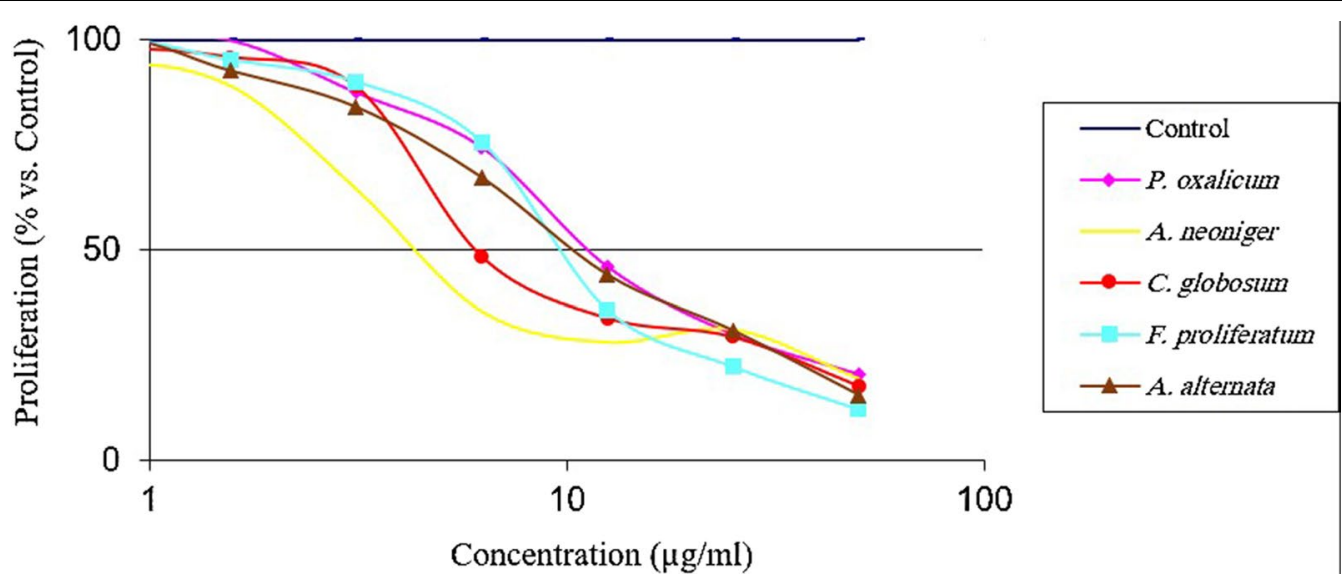

Fig. 2 Antiproliferative effect on HUVEC 


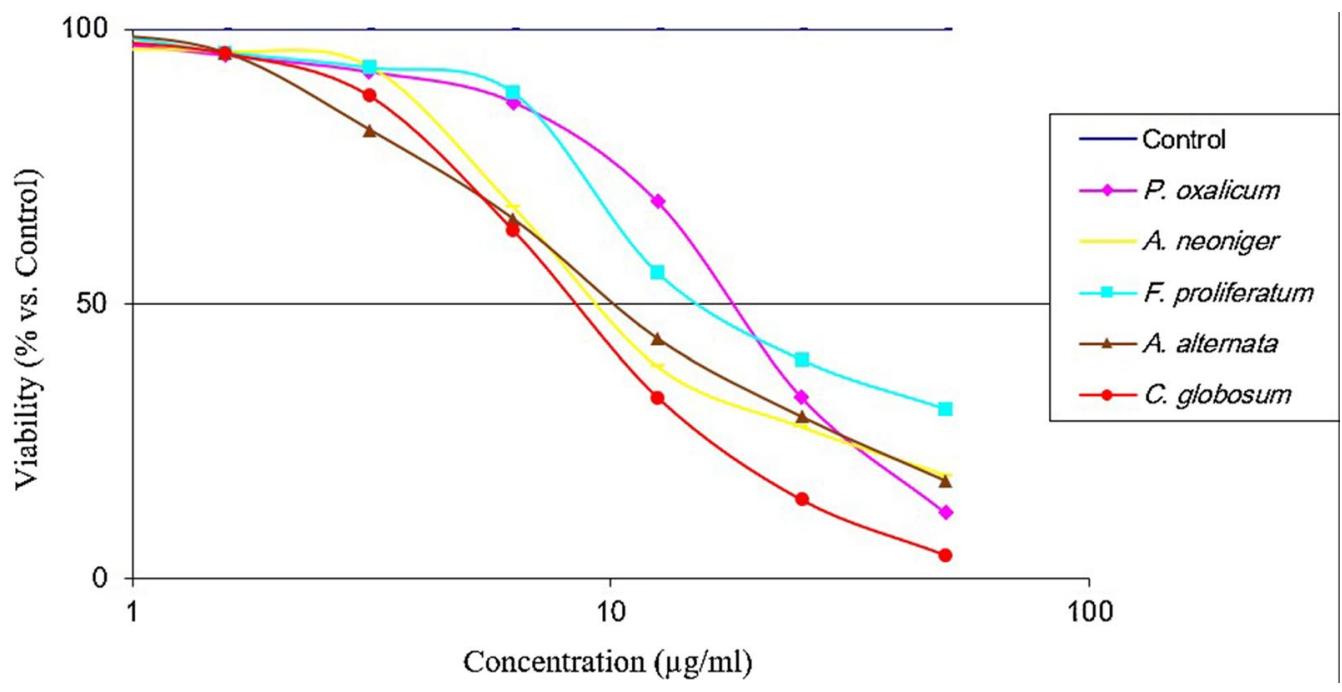

Fig. 3 Cytotoxicity on HeLa

respectively. The extract of C. globosum exhibited significantly higher cytostatic activity against HUVEC $\left(\mathrm{GI}_{50}=6.85 \mu \mathrm{g} \mathrm{mL}^{-1}\right)$ than it exerted against $\mathrm{K}-562$ cell line $\left(\mathrm{GI}_{50}=13.75 \mu \mathrm{g} \mathrm{mL}^{-1}\right)$.

\section{Discussion}

The antimicrobial activities of the plant Ficus carica were previously studied, and MIC values ranging from 0.313 to $5 \mathrm{mg} / \mathrm{mL}$ against different bacterial strains were obtained for the plant extract (Joeng et al. 2009). In addition, the antifungal effects of the plant extract were also investigated against $C$. albicans and Microsporum canis and growth inhibitions with MIC values of $500 \mu \mathrm{g} / \mathrm{mL}$ and $75 \mu \mathrm{g} / \mathrm{mL}$, respectively, were observed for it (Aref 2010). Interestingly, also endophytic extracts of this host plant were found in our study to exert both antibacterial and antifungal activities against several test strains. This result is not surprising since endophytes were often reported to exert antimicrobial activities which are assumed to be part of their defense to the plant against invading pathogens. This antimicrobial effect observed for endophytes suggests their competition with other microorganisms for space and nutrition within the host plant. Through their antimicrobial effect, they prevent several species from invading their habitat. Consequently, they provide protection to the plant and render it more resistant to pathogenic attack (Glass et al. 2000).

Even the anticancer activity previously reported in a study for the plant extract against Huh7it liver cancer cells $\left(\mathrm{IC}_{50}\right.$ value of $\left.>653 \mu \mathrm{g} / \mathrm{mL}\right)$ seems to be supported by endophytes harboring this medicinal plant since all five endophytic extracts under investigation exerted antiproliferative effects against HUVEC and K-562 cell lines in addition to cytotoxicity against HeLa cells. These results further support the assumption that endophytes of $F$. carica contribute to its biological activities.

All extracts were found to exert cytotoxic activity against HeLa cell line with the highest cytotoxic effect observed for $A$. neoniger and highest antiproliferative action exhibited by $A$. neoniger against HUVEC. Highest antifungal, cytotoxic and antiproliferative effects were observed for the extracts of strains $A$. neoniger and C. globosum which makes them candidates for further studies for investigation of their bioactive metabolites. Since it has been previously assumed that endophytes of the same host plant do not compete with each other and their growth mainly depends on effective communication with other species (Glass et al. 2000), endophytes of $F$. carica seem to provide protection to the host plant from microbial attacks while living in a "peaceful" symbiotic relationship with their neighboring endophytic fungi.

\section{Conclusion}

In conclusion, the medicinal plant Ficus carica growing in the tropical environment of Makkah, KSA, has been selected for investigation of its endophytes. Five fungal species were isolated from it and identified as Chaetomium globosum, Penicillium oxalicum, Alternaria alternata, Fusarium proliferatum and Aspergillus neoniger. The extracts of these endophytic fungi were subjected to antimicrobial and anticancer activity tests and showed potent antimicrobial and cytotoxic effects. This suggests that endophytes of $F$. carica contribute at least partially to the plant's reported anticancer and antimicrobial activities and provides a promising source of bioactive natural products with therapeutic potential. 


\begin{abstract}
Abbreviations
MIC: Minimum inhibitory concentration; $\mathrm{CC}_{50}$ : 50\% Cytotoxic concentration; $\mathrm{Gl}_{50}$ : Growth inhibition by 50\%; HMBC: Heteronuclear multiple bond correlations; NMR: Nuclear magnetic resonance; HUVEC: Human umbilical vein endothelial cell; K-562: Human immortalized myelogenous leukemia cell line; HeLa: Human immortal cervical cancer cell line; HRESIMS: High-resolution electrospray ionization mass spectrometry; DNA: Deoxyribonucleic acid; ITS: Internal transcribed spacer; PDA: Potato dextrose agar; DMEM: Dulbecco's modified Eagle's medium; DMSO: Dimethyl sulfoxide; RPMI: Roswell Park Memorial Institute.
\end{abstract}

\section{Acknowledgements}

The authors would like to thank the Deanship of Scientific Research at Umm Al-Qura University for supporting this work by a Grant Code: 19-MED-1-03-0005.

\section{Authors' contributions}

RA designed, supervised the work and wrote the manuscript. MM collected and interpreted the data. GA collected and identified the plant and evaluated data. All authors have read and approved the manuscript.

\section{Funding}

This work was fully supported and funded by a grant code 19-MED-1-03-0005 from the Deanship of Scientific Research at Umm Al-Qura University which provided all required materials, basic supplies, manpower and analysis.

\section{Availability of data and materials}

All data and material are available upon request.

\section{Declarations}

\section{Ethics approval and consent to participate}

Not applicable.

\section{Consent for publication}

Not applicable.

\section{Competing interests}

The authors declare that they have no competing interests.

\section{Author details}

1 Pharmacognosy Department, Faculty of Pharmacy, Umm Al-Qura University, Makkah, Kingdom of Saudi Arabia. ${ }^{2}$ Pharmaceutical Chemistry Department, Faculty of Pharmacy, Umm Al-Qura University, Makkah, Kingdom of Saudi Arabia. ${ }^{3}$ Pharmacognosy Department, College of Pharmacy, Najran University, Najran, Kingdom of Saudi Arabia.

Received: 7 January 2021 Accepted: 22 February 2021

Published online: 02 March 2021

\section{References}

Abd El Raheim MD et al (2013) Chemical constituents and protective effect of Ficus ingens (Miq.) on carbon tetrachloride-induced acute liver damage in male Wistar albino rats. J Saudi Chem Soc 17:125-133

Abdou R et al (2010) Botryorhodines A-D, antifungal and cytotoxic depsidones from Botryosphaeria rhodina, an endophyte of the medicinal plant Bidens pilosa. Phytochemistry 71:110-116

Afonin SR et al (2003) 4-fluorophenylglycine as a label for 19F NMR structure analysis of membrane-associated peptides. Chem Biochem 4:1151-1163
Aref HL et al (2010) In vitro antimicrobial activity of four Ficus carica latex frac tions against resistant human pathogens (antimicrobial activity of Ficus carica latex). Pak J Pharm Sci 23:53-58

Barnett HL, Hunter BB (1998) Illustrated genera of imperfect fungi. APS Press, St. Paul

Barolo MI, Ruiz Mostacero N, Lopez SN (2014) Ficus carica L. (Moraceae): an ancient source of food and health. Food Chem 164:119-127

Elix JA, Lajide L, Galloway DJ (1982) Metabolites from the Lichen Genus Psoroma. Aust J Chem 35:2325-2333

Fernandez E et al (1998) Photoprotector capacity of lichen metabolites assessed through the inhibition of the 8-methoxypsoralen photobinding to protein. J Photochem Photobiol B 42:195-201

Glass NL, Jacobson DJ, Shiu PKT (2000) The Genetics of hyphal fusion and vegetative incompatibility in filamentous ascomycete fungi. Annu Rev Genet 34:R165-R186

Joeng MR, Kim HY, Cha JD (2009) Antimicrobial activity of methanol extract from Ficus carica leaves against oral bacteria. J Bacteriol Virol 39:97-102

Kour D et al (2020) Endophytic fungi from medicinal plants: biodiversity and biotechnological applications. Microbial Endophytes 273-305

Macabeo APG et al (2013) Antitubercular and cytotoxic constituents from Goniothalamus gitingensis Rec. Nat Prod 8:41-45

Mawa S, Husain K, Jantan I (2013) Ficus carica L. (Moraceae): Phytochemistry, traditional use and biological activities. Evid Based Complement Alternat Med 974256

Michaelsen A et al (2006) Application of molecular techniques for identification of fungal communities colonising paper material. Int Biodeterioration Biodegrad 58:133-141

Purnamasari R et al (2019) Anticancer activity of methanol extract of Ficus carica leaves and fruits against proliferation, apoptosis and necrosis in Huh7it cells. Cancer Inf 18:1-7

Raja HA et al (2017) Fungal identification using molecular tools: a primer for the natural products research community. J Nat Prod 80:756-770

Rosli NM, Ashari KIAH, Azmi NSA (2020) Isolation and preliminary screening of endophytic fungi from Ficus carica for biocontrol and phosphate solubilization. Environ Ecosyst Sci 4:77-84

Rychlik W, Spencer WJ, Rhoads RE (1990) Optimization of the annealing temperature for DNA amplification in vitro. Nucleic Acids Res 18:6409-6412

Saikkonen K et al (2004) Evolution of endophyte-plant symbioses. Trends Plant Sci 9:275-280

Stevens RB (1981) Mycology guidebook. University of Washington Press, Seattle

Strobel G (2006) Harnessing endophytes for industrial microbiology. Curr Opin Microbiol 9:240-244

Suryanarayanan TS, Vijaykrishna D (2001) Fungal endophytes of aerial roots of Ficus benghalensis. Fungal Divers 8:155-161

Verma VC, Kharwar RN, Strobel GA (2009) Chemical and functional diversity of natural products from plant associated endophytic fungi. Nat Prod Commun 4:1511-1532

Vieira LM, Kijjoa A (2005) Naturally-occurring xanthones: recent developments. Curr Med Chem 12:2413-2446

Wayne PA (2002) Reference method for broth dilution susceptibility testing of filamentous fungi. Approved Standard. M38-A, USA, NCCls

Wayne P, USA, NCCls (2002) National Committee for Clinical Laboratory Standards: Reference Method for Broth Dilution Susceptibility Testing of Filamentous Fungi. Approved Standard 22

Zhang HW, Song YC, Tan RX (2006) Biology and chemistry of endophytes. Nat Prod Rep 23:753-771

\section{Publisher's Note}

Springer Nature remains neutral with regard to jurisdictional claims in published maps and institutional affiliations. 